\title{
Understanding Pulp Delignification by Laccase-Mediator Systems through Isolation and Characterization of Lignin-Carbohydrate Complexes
}

Xueyu Du, ${ }^{\dagger}$ Jiebing Li, ${ }^{* \dagger}$ Göran Gellerstedt, ${ }^{\dagger}$ Jorge Rencoret, ${ }^{\ddagger}$ José C. Del Río, ${ }^{\ddagger}$ Angel T. Martínez, and Ana Gutiérrez

${ }^{\dagger}$ Department of Fibre and Polymer Technology, Royal Institute of Technology, KTH, Teknikringen 56-58, SE-10044 Stockholm, Sweden

${ }^{\ddagger}$ Instituto de Recursos Naturales y Agrobiología de Sevilla, CSIC, P.O. Box 1052, E-41080 Seville, Spain

${ }^{\S}$ Centro de Investigaciones Biológicas, CSIC, Ramiro de Maeztu 9, E-28040 Madrid, Spain

ABSTRACT: The effects and mechanism of pulp delignification by laccases in the presence of redox mediators have been investigated on unbleached eucalyptus kraft pulp treated with laccases from Pycnoporus cinnabarinus (PcL) and Myceliophthora thermophila (MtL) and 1-hydroxybenzotriazole (HBT) and methyl syringate $(\mathrm{MeS})$ as mediators, respectively. Determination of the corrected $\kappa$ number in eucalyptus pulps after the enzymatic treatments revealed that the PcL-HBT system exhibited a more remarkable delignification effect than the $\mathrm{MtL}-\mathrm{MeS}$ system. To obtain further insight, lignin-carbohydrate complexes were fractionated and subsequently characterized by nuclear magnetic resonance, thioacidolysis (followed by gas chromatography and size exclusion chromatography), and pyrolysis-gas chromatography-mass spectrometry (pyrolysis-GCMS) analyses before and after the enzymatic treatments and their controls. We can conclude that the laccase-mediator treatments altered the lignin structures in such a way that more lignin was recovered in the xylan-lignin fractions, as shown by Klason lignin estimation, with smaller amounts of both syringyl (S) and guaiacyl (G) uncondensed units, as shown by thioacidolysis and gas chromatography, especially after the PcL-HBT treatment. The laccase-mediator treatment produced oxidation at $\mathrm{C} \alpha$ and cleavage of $\mathrm{C} \alpha$ and $\mathrm{C} \beta$ bonds in pulp lignin, as shown by pyrolysis-GC-MS. The general mechanism of residual lignin degradation in the pulp by laccase-mediator treatments is discussed in light of the results obtained.

\section{INTRODUCTION}

Lignin removal is a central issue in paper pulp manufacturing, which has been traditionally handled by chemical pulping and bleaching. Recently, there is a general trend worldwide to apply biotechnology in lignin removal using, e.g., ligninolytic enzymes as safer and more environmentally friendly alternatives to the chlorine-containing bleaching chemicals. Among different ligninolytic enzymes, lignin peroxidase $(\mathrm{LiP}){ }^{1}$ manganese peroxidase $(\mathrm{MnP}){ }^{2}$ and versatile peroxidase $(\mathrm{VP})^{3}$ are three well-known enzymes secreted by fungi with high oxidation capacities. LiP can directly oxidize lignin constituents; $\mathrm{MnP}$ generates $\mathrm{Mn}^{3+}$ that serves as a diffusible oxidizer, and VP combines the degradative abilities of $\mathrm{LiP}$ and $\mathrm{MnP} .{ }^{4}$ As a fourth ligninolytic enzyme, laccase belongs to the largest group of blue multicopper oxidases, which exists in many plants, fungi, and microorganisms. Laccase has outstanding redox ability, by which a wide range of aromatic substrates could be oxidized into phenoxy radicals under the catalysis of its copper ions using oxygen as the electron acceptor and producing water as a byproduct. $^{5-8}$

In general, laccase is the most promising ligninolytic enzyme for industrial delignification applications because it is more readily available and easier to manipulate than $\mathrm{LiP}, \mathrm{MnP}$, and VP. However, unlike the peroxidases mentioned above, this green biocatalyst possesses a relatively low redox potential $(\leq 0.8 \mathrm{~V})$. Thus, its direct application for lignin degradation would be limited to the oxidation of the phenolic lignin moiety because nonphenolic structures have a redox potential of $>1.3$ V. Laccase alone is unsuitable for lignin degradation in practice because there is only a small percentage of the phenolic groups in the entire lignin structure, $, 9,10$ and on the other hand, there is a limited ability of the bulk laccase molecule to penetrate into the cell wall. These limitations have, however, been overcome through mimicking the nature by using redox mediators, known as building a laccase-mediator system (LMS), which can achieve the oxidation of nonphenolic lignin. ${ }^{11}$ Mechanistically, the small mediator molecule is first oxidized or activated by the laccase, and then the mediator penetrates the compact lignocellulosic structure more easily than the enzyme and thus realizes the oxidation of lignin inside the sample.

Received: May 14, 2013

Revised: July 5, 2013

Published: July 9, 2013 
The overall delignification efficiency of the LMS depends on the laccase and mediator used and their combination. An effective LMS for lignin degradation should have the following features: an effective oxidation of the mediator, a high redox potential of the activated mediator for effectively oxidizing nonphenolic lignin, and sufficient stability to prevent the laccase from being inactivated by the free radical form of the mediator. Among many combinations investigated in the literature, the Myceliophthora thermophila laccase (MtL) with methyl syringate (MeS) and Pycnoporus cinnabarinus laccase (PcL) with 1-hydroxybenzotriazole (HBT) are successful examples of low- and high-redox potential laccases using natural and synthetic mediators, respectively, as outlined below. The lignin degradation capacity of the MtL-MeS system has been demonstrated in experiments with model lignin compounds ${ }^{12}$ and biobleaching of $\mathrm{flax}^{13}$ or eucalyptus pulp. $^{14,15}$ Additionally, the effectiveness of the MtL-MeS system in deinking ${ }^{16}$ and pitch removal ${ }^{14}$ has also been shown. Likewise, the efficiency of the PcL-HBT system has been revealed via redox chemistry research, ${ }^{17}$ reactions on nonphenolic lignin models, ${ }^{18}$ biobleaching of flax ${ }^{19,20}$ or eucalyptus pulp, $^{21,22}$ removal of pitch from different pulps, ${ }^{23-25}$ and delignification of woody and nonwoody feedstock. ${ }^{26}$

To determine the potential of an LMS as an industrial biocatalyst, it is important to understand the biodegradation mechanism and to evaluate and optimize the efficiency. At a theoretical level, this has commonly been achieved by performing LMS tests on lignin models and synthetic lignin structure (e.g., DHPs). For example, commercial lignosulfonates were used to investigate the molecular mass increase effect caused by laccase catalysis. ${ }^{27}$ At the practical level on the lignin macromolecule in the real paper pulps, the LMS tests have conventionally been investigated by measuring, e.g., the $\kappa$ number (a rough estimation of lignin content), brightness, and viscosity. Further evaluations via pulp analyses by thermogravimetry, ${ }^{28}$ microscopy, ${ }^{29}$ one-dimensional ${ }^{30}$ and two-dimensional nuclear magnetic resonance (NMR), ${ }^{31}$ Fourier transform infrared spectroscopy (FTIR), ${ }^{22,30}$ X-ray photoelectron spectroscopy (XPS), ${ }^{32}$ and analytical pyrolysis [pyrolysis-gas chromatography-mass spectrometry (Py-GC-MS)] using lignin markers, ${ }^{33}$ lignin:carbohydrate ratios, ${ }^{21}$ or ratios of phenylmethane-type compounds $(\mathrm{Ph}-\mathrm{C} 1)$, phenylethane-type compounds $(\mathrm{Ph}-\mathrm{C} 2)$, and phenylpropane-type compounds $(\mathrm{Ph}-\mathrm{C} 3)$ have been reported. ${ }^{33}$

It is now known that the lignin is present in biomass as a lignin-carbohydrate complex (LCC). ${ }^{34}$ After chemical pulping, the residual lignin still presents as LCC structures. ${ }^{35}$ Therefore, fractionation of LCC structures before and after laccasemediator treatment followed by structural characterization will provide more profound insights into the lignin biodegradation by the LMS. This has been demonstrated by using Streptomyces ipomoea laccase together with acetosyringone as a mediator where different LCC structures were fractionated following the universally applicable LCC fractionation protocol developed at $\mathrm{KTH}^{34}$ followed by structural characterizations using thioacidolysis-GC and -size exclusion chromatography (SEC) and NMR analysis. ${ }^{36}$ To improve our understanding of the LMS, the MtL-MeS and PcL-HBT combinations mentioned above have been applied in this study of unbleached kraft pulp from eucalyptus (Eucalyptus globulus) followed by a comprehensive structural characterization of pulp LCCs to reveal the presence, reactivity, and biodegradation reaction mechanism of the residual lignin in the kraft pulp by the LMS.

\section{EXPERIMENTAL SECTION}

Samples. Industrial unbleached E. globulus kraft pulp was provided by the ENCE pulp mill (Pontevedra, Spain). Its $\kappa$ number and hexenuronic acid (HexA) content were 13.7 and $57.8 \mu \mathrm{mol} / \mathrm{g}$, respectively.

Laccases. A commercial fungal laccase from the ascomycete $M$. thermophila (MtL), provided by Novozymes (Bagsvaerd, Denmark), and a fungal laccase preparation obtained from a laccase-hyperproducing strain of the basidiomycete $P$. cinnabarinus $(\mathrm{PcL})$, provided by Beldem (Andenne, Belgium), were used in this study. Laccase activity was measured as the initial velocity during oxidation of $5 \mathrm{mM}$ 2,2'-azinobis(3-ethylbenzothiazoline-6-sulfonic acid) (ABTS) (from Roche) to its cation radical $\left(\varepsilon_{436}=29300 \mathrm{M}^{-1} \mathrm{~cm}^{-1}\right)$ in $0.1 \mathrm{M}$ sodium acetate $\left(\mathrm{pH} \mathrm{5)}\right.$ ) at $24{ }^{\circ} \mathrm{C}$. The laccase activities of the two enzyme preparations were 945 and 45 units $/ \mathrm{mL}$, respectively. One activity unit was defined as the amount of enzyme transforming $1 \mu \mathrm{mol}$ of ABTS/ $\mathrm{min}$. Same loading in terms of laccase activity (20 units/g of pulp) was used for comparative studies.

Mediators. The mediators methyl syringate (MeS, methyl 4hydroxy-3,5-dimethoxybenzoate) from Alfa Aesar (Karlsruhe, Germany) and 1-hydroxybenzotriazole (HBT) from Sigma-Aldrich (Steinheim, Germany) were used.

Laccase-Mediator Treatment. Pulp treatments with the MtL$\mathrm{MeS}$ system were conducted using $10 \mathrm{~g}$ (dry weight) of pulp at $3 \%$ consistency $(\mathrm{w}: \mathrm{w})$ in $50 \mathrm{mM}$ sodium dihydrogen phosphate buffer ( $\mathrm{pH} 6$ ). Laccase loading was 20 units/g of pulp, and the concentration of $\mathrm{MeS}$ in the reaction mixture was kept at $6.75 \mathrm{mM}$. The treatments were conducted in $500 \mathrm{~mL}$ flasks with $\mathrm{O}_{2}$ bubbling, and the mixtures were placed in a thermostatic shaker at $170 \mathrm{rpm}$ and $50{ }^{\circ} \mathrm{C}$ for $12 \mathrm{~h}$. Pulp treatments with PcL were performed as described above for $\mathrm{MtL}$, but using $50 \mathrm{mM}$ sodium tartrate $(\mathrm{pH} 4)$ as a buffer and HBT $(3 \mathrm{mM})$ as a mediator. Controls without laccase and mediator and controls including laccase alone (without mediator) were also performed. The different pulps obtained, which are listed in Table 1, were extracted with acetone in a Soxhlet extractor for $24 \mathrm{~h}$ and further analyzed as extractives-free pulp samples.

Table 1. $\kappa$ Numbers and Hexenuronic Acid (HexA) Contents of Eucalyptus Unbleached Kraft Pulps after Laccase-Mediator Treatments with MtL-MeS and PcLHBT Systems Compared with the Initial Untreated Material, Controls without Laccases (control pH 6 and control pH 4), and Controls with Only Laccase (MtL and PcL)

\begin{tabular}{lccc}
\multicolumn{1}{c}{ sample } & $\kappa$ number & HexA $(\mu \mathrm{mol} / \mathrm{g})$ & ${\text { corrected } \kappa \text { number }^{a}}^{\text {initial pulp }}$ \\
control pH 6 & 13.7 & 58 & 8.7 \\
MtL & 13.5 & 57 & 8.6 \\
MtL-MeS & 13.0 & 57 & 8.1 \\
control pH 4 & 12.3 & 57 & 7.4 \\
PcL & 13.0 & 56 & 8.2 \\
PcL-HBT & 13.1 & 56 & 8.3 \\
\end{tabular}

${ }^{a} \mathrm{~A} \kappa$ number that better reflects the true lignin content after subtraction of the pulp $\kappa$ number by the contribution from HexA using the conversion factor of $0.086 \kappa$ number per micromole per gram of HexA. $^{43}$

LCC Fractionation. LCC fractionation was performed as described previously. ${ }^{34,37}$ After the samples had been Wiley milled to particle sizes smaller than 40 mesh and subjected to a subsequent $12 \mathrm{~h}$ ballmilling using the mill from SiebTechnik (Mulheim, Germany), 500 $\mathrm{mg}$ of the milled pulp sample was suspended and then dissolved in 10 $\mathrm{mL}$ of a dimethyl sulfoxide (DMSO) $/ 40 \%$ tetrabutylammonium hydroxide (TBAH) solution [1:1 (v:v)] that was stirred for $4 \mathrm{~h}$. The sample solution was then dispersed into $100 \mathrm{~mL}$ of deionized water while being stirred and was allowed to stand overnight for the formation of high-molecular mass precipitates that had low solubility 
Table 2. Yields (percentages of starting pulp), Lignin Contents (Klason lignin, percentage on LCC), Lignin Compositions in Terms of Uncondensed G and S Lignin Units (micromoles per gram) Released by Thioacidolysis, and Carbohydrate Compositions of Glucan-Lignin and Xylan-Lignin Fractions after MtL-MeS and PcL-HBT Treatments Compared with the Controls without Laccases or a Mediator (control pH 6 and control pH 4)

\begin{tabular}{|c|c|c|c|c|c|c|c|c|c|c|}
\hline & & & \multicolumn{3}{|c|}{ lignin } & \multicolumn{5}{|c|}{ carbohydrate (relative \%) } \\
\hline \multicolumn{2}{|c|}{ sample } & yield (\%) & lignin (\%) & G units & $S$ units & Ara & Xyl & Man & Gal & Glu \\
\hline \multirow[t]{2}{*}{ control pH 6} & glucan-lignin & $\sim 80$ & 1.4 & 0 & 0 & 1.9 & 5.4 & 0.8 & 0 & 91.9 \\
\hline & xylan-lignin & $\sim 20$ & 4.5 & 7 & 18 & 4.3 & 88.4 & 0 & 2.3 & 5.0 \\
\hline \multirow[t]{2}{*}{$\mathrm{MtL}-\mathrm{MeS}$} & glucan-lignin & $\sim 80$ & 1.5 & 0 & 0 & 2.8 & 4.9 & 0.7 & 0 & 91.5 \\
\hline & xylan-lignin & $\sim 20$ & 7.3 & 5 & 15 & 2.0 & 92.0 & 0 & 1.9 & 4.1 \\
\hline \multirow[t]{2}{*}{ control pH 4} & glucan-lignin & $\sim 80$ & 2.4 & 0 & 0 & 3.1 & 4.9 & 0.7 & 0 & 91.3 \\
\hline & xylan-lignin & $\sim 20$ & 2.7 & 5 & 17 & 4.1 & 90.9 & 0 & 2.0 & 3.0 \\
\hline \multirow[t]{2}{*}{ PcL-HBT } & glucan-lignin & $\sim 80$ & 0.4 & 0 & 0 & 2.6 & 5.3 & 0.6 & 0 & 91.5 \\
\hline & xylan-lignin & $\sim 20$ & 6.7 & 2 & 5 & 2.6 & 93.6 & 0 & 1.6 & 2.2 \\
\hline
\end{tabular}

in the diluted DMSO/TBAH solution. Separation of the precipitates by centrifugation was conducted, and then the precipitates were washed with deionized water until neutral $\mathrm{pH}$ was reached. The washed precipitates were obtained after being freeze-dried as glucanlignin. From the centrifugation supernatant, xylan-lignin, which had a low molecular mass and a high solubility in the diluted DMSO/TBAH solution, was obtained after ultrafiltration (molecular mass cutoff of $1000 \mathrm{Da}$ ) for $48 \mathrm{~h}$ and subsequent freeze-drying.

Lignin Content and Polysaccharide Composition. The $\kappa$ number (ISO 302) and the HexA content ${ }^{38}$ were determined for all pulp samples. The Klason lignin and carbohydrate composition of LCCs were determined according to TAPPI Standards T 222 om-06 and T $249 \mathrm{~cm}-00$, respectively.

NMR Analyses of LCC. ${ }^{1} \mathrm{H}$ NMR spectra of the xylan-lignin species were recorded after dissolution in DMSO- $d_{6}$ on a Bruker Advance $400 \mathrm{MHz}$ instrument using the standard Bruker pulse program at room temperature. ${ }^{1} \mathrm{H}$ NMR spectra of the glucan-lignin fractions were recorded after acetylation ${ }^{39}$ and dissolution in chloroform- $d$.

Thioacidolysis-GC and -SEC of LCCs. The thioacidolysis reaction was conducted as described previously. ${ }^{40}$ The thioacidolysis product mixture $(\sim 6 \mathrm{mg})$ was silylated for $30 \mathrm{~min}$ at room temperature with $100 \mu \mathrm{L}$ of pyridine and $\mathrm{N}, \mathrm{O}$-bis(trimethylsilyl)trifluoroacetamide (BSTFA) [1:1 (v:v)] before being analyzed by GC to quantify the monomeric degradation products, i.e., the uncondensed syringyl (S) and guaiacyl (G) units present in the sample. GC analysis was conducted using a DB-5MS column with helium as the carrier gas. The initial temperature was $150{ }^{\circ} \mathrm{C}$ for $2 \mathrm{~min}$, and it was then increased at a rate of $5{ }^{\circ} \mathrm{C} / \mathrm{min}$ to $170{ }^{\circ} \mathrm{C}$, followed by an increase at a rate of $25{ }^{\circ} \mathrm{C} / \mathrm{min}$ to $330{ }^{\circ} \mathrm{C}$. The injector temperature was $230{ }^{\circ} \mathrm{C}$. Another portion of the thioacidolysis product mixture $(\sim 20 \mathrm{mg})$ was acetylated and analyzed by SEC to evaluate the size distribution of lignin fragments and the extent of lignin condensation. SEC analysis was performed using a Waters system with a Waters 2487 UV detector at $280 \mathrm{~nm}$. The analyses were conducted at room temperature using tetrahydrofuran (THF) as the eluent, at a flow rate of $0.8 \mathrm{~mL} / \mathrm{min}$. The samples were dissolved in THF and injected onto three Ultrastyragel columns (HR 2.5, HR 2, and HR 4) coupled in series. The SEC system was calibrated with polystyrene standards in the molecular mass range from 484 to $17900 \mathrm{Da}$.

Py-GC-MS of LCC. Py-GC-MS analysis of an approximately $100 \mu \mathrm{g}$ sample were performed with a model 3030 microfurnace pyrolyzer (Frontier Laboratories Ltd.) connected to an Agilent 6890 GC/MS system equipped with a DB-1701 fused-silica capillary column [60 m $\times 0.25 \mathrm{~mm}$ (inside diameter), $0.25 \mu \mathrm{m}$ film thickness] and an Agilent 5973 mass selective detector (EI $70 \mathrm{eV}$ ). Pyrolysis was performed at $500{ }^{\circ} \mathrm{C}$. The $\mathrm{GC}$ oven temperature was programmed from $45^{\circ} \mathrm{C}(4 \mathrm{~min})$ to $280{ }^{\circ} \mathrm{C}(10 \mathrm{~min})$ with the heating rate of $4{ }^{\circ} \mathrm{C} /$ $\mathrm{min}$. Helium served as the carrier gas $(2 \mathrm{~mL} / \mathrm{min})$.

\section{RESULTS AND DISCUSSION}

Lignin Content in Whole Eucalyptus Enzymatically Treated Pulps. The delignification by the LMS was explored using one industrial eucalyptus kraft pulp. The two wellestablished combinations of different laccases and different mediators were investigated, MtL with MeS and PcL with HBT. The two treatments were conducted at $\mathrm{pH} 6$ and 4 , which were known as the optimal conditions of each enzyme, respectively. ${ }^{22,31,41}$ Control experiments were also performed (Table $1)$.

The biodegradation effects of the LMS treatments were first analyzed on the pulp samples by $\kappa$ number and hexenuronic acid (HexA) content determination for evaluation of the removal of lignin and HexA, a mimicking lignin structure formed during kraft pulping. For example, HexA consumes $\mathrm{MnO}_{4}{ }^{-}$during $\kappa$ estimation and is thus a contributor to the pulp $\kappa$ number other than the lignin. ${ }^{42}$ Therefore, to better express the lignin content by the $\kappa$ number, the corrected $\kappa$ number was calculated by subtraction of the $\kappa$ number contribution from HexA from the pulp $\kappa$ number by the conversion factor of $0.086 \kappa$ number per micromole per gram of HexA $^{43}$ (Table 1).

As shown in Table 1, the delignification produced by the MtL-MeS system (corrected $\kappa$ number reduction of $8.7-7.4$ $=1.3$ units) was weaker than that with the PcL-HBT system (corrected $\kappa$ number reduction of $8.7-6.3=2.4$ units). This is in agreement with the difference in the redox potential values of the two enzymes, 450 and $750 \mathrm{mV}$ for $\mathrm{MtL}$ and $\mathrm{PcL}$, respectively. ${ }^{18}$ The delignification difference may also come from the difference in the mediators used. In addition, because the MeS used in a laccase-mediator treatment was known to be capable of grafting onto the fiber (ref 14 and see below), which will increase the $\kappa$ number, ${ }^{44}$ the actual delignification effect of the MtL-MeS system could be larger than the observed $\kappa$ number of 1.4. Interestingly, the control experiment with a buffer solution of $\mathrm{pH} 4$ removed a part of the residual lignin $(8.6-8.1=0.5$ unit $)$, while the control experiment at pH 6 did not delignify the pulp (corrected $\kappa$ number of $8.6 \mathrm{vs}$ 8.7 for the initial pulp). The removable part of lignin would be a type of acid-leachable lignin located at the pulp surface. Very obviously, without a mediator both enzymes had only gentle and similar biodegradation capabilities, 0.6 and 0.4 corrected $\kappa$ unit reduction for MtL and PcL, respectively. Mechanistically, the lignin removed by the laccases without mediators should be those moieties located at the pulp surface and of the phenolic 
group rich type. As shown in Table 1, no HexA removal was observed for any of the pulp samples investigated here.

Characterization of LCC from Enzymatically Treated

Pulps. In this study, we have fractionated and characterized lignin-carbohydrate complexes (LCCs) following the universally applicable protocols previously developed. ${ }^{34}$ Pulps treated with the LMS and their corresponding controls without laccase and mediator were fractionated into two LCCs, one glucanlignin fraction, the major sugar being glucose $(>90 \%)$, and one xylan-lignin fraction, the major sugar being xylose $(>88 \%)$ (Table 2).

Comparatively, glucan-lignin fractions are the dominating LCC fractions ( $\sim 80 \%$ of the yield) with smaller amounts of lignin (0.4-2.4\%), while xylan-lignin fractions (20\% yield) contain larger amounts of residual lignin (2.7-7.3\%) (Table 2). Here we point out that because of limited amounts of ballmilled pulps used in the experiments $(\sim 500 \mathrm{mg})$ there were weighing errors for the LCC Klason lignin values obtained. Nevertheless, it is certain that higher Klason lignin contents were observed in the xylan-lignin fractions after the LMS treatments, 7.3\% (MtL-MeS) versus 4.5\% (control pH 6) and $6.7 \%$ (PcL-HBT) versus $2.7 \%$ (control pH 4). This could be attributable to the lignin biodegradation. When part of the lignin from the glucan-lignin fractions was degraded and free from the glucan part, it will remain in the solution and eventually be a part of the xylan-lignin fractions after the freeze-drying (see Experimental Section). Because of the experimental errors in Klason lignin determination mentioned above, a decrease in lignin content in the glucan-lignin fractions was not observed in the case of the $\mathrm{MtL}-\mathrm{MeS}$ system $[1.5 \%(\mathrm{MtL}-\mathrm{MeS})$ vs $1.4 \%$ (control pH 6)], while the decrease was evident in the case of the PcL-HBT system $[0.4 \%$ (PcLHBT) vs $2.4 \%$ (control $\mathrm{pH} 4)$ ].

${ }^{1} \mathrm{H}$ NMR Analysis. ${ }^{1} \mathrm{H}$ NMR was applied to characterize the structures of the fractionated LCCs. Because it was difficult to dissolve the glucan-lignin fraction in any common NMR solvent, acetylation was performed to enhance the solubility of the sample in chloroform- $d$. After the acetylation, all glucanlignin fractions from the four pulp samples (Table 2) gave ${ }^{1} \mathrm{H}$ NMR spectra very similar to each other. The typical spectrum of the PcL-HBT-treated sample is shown in Figure 1A, where the six types of proton signals from glucosyl units are clearly observed from 3.53 to $5.06 \mathrm{ppm}$. In the region for aromatic protons, no lignin signals could be noticed even after a signal magnification. This is due to the fact that the lignin contents were low (0.4-2.4\% Klason lignin).

All the xylan-lignin fractions could be readily dissolved in DMSO- $d_{6}$ for ${ }^{1} \mathrm{H}$ NMR analysis. Their ${ }^{1} \mathrm{H}$ NMR spectra were also considerably similar to each other. The example from the pulp treated with the PcL-HBT system is depicted in Figure 1B; the five types of proton signals from xylosyl units are located from 3.04 to $4.26 \mathrm{ppm}$. The aromatic proton signals are barely noticeable compared with the signals of the carbohydrate parts, which is due to the small quantity of lignin in these LCC fractions $(2.7-7.3 \%$ of Klason lignin). After signal magnification of the 6.0-7.0 ppm region as performed for the glucanlignin NMR spectra, the lignin aromatic signals could then be more clearly seen. The broad peak shape of the signals confirms the presence of the lignin as a part of the xylan-lignin fraction. The much stronger aromatic signals in the xylan-lignin fractions than in the glucan-lignin fractions can be attributed to the higher lignin contents.

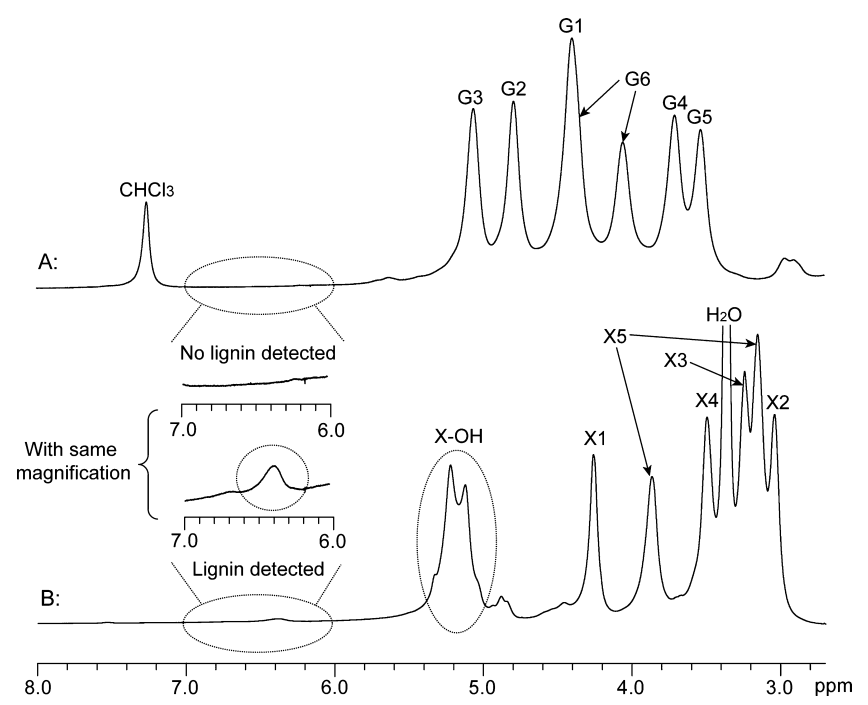

Figure 1. ${ }^{1} \mathrm{H}$ NMR spectra of LCCs from eucalyptus unbleached kraft pulp treated with the PcL-HBT system. (A) Acetylated glucan-lignin fraction dissolved in $\mathrm{CDCl}_{3}$. (B) Xylan-lignin fraction dissolved in DMSO- $d_{6}$. In the spectra, G1 (4.40 ppm), G2 (4.79 ppm), G3 (5.06 ppm), G4 (3.71 ppm), G5 (3.53 ppm), and G6 (4.05 and $4.40 \mathrm{ppm})$ are the characteristic proton signals from glucosyl units. X1 (4.26 ppm), X2 (3.04 ppm), X3 (3.25 ppm), X4 (3.50 ppm), and X5 (3.16 and $3.87 \mathrm{ppm})$ are the characteristic proton signals from xylosyl units. $\mathrm{X}-\mathrm{OH}(5.13$ and $5.23 \mathrm{ppm}$ ) originates from protons of $-\mathrm{OH}$ groups of xylosyl units.

Thioacidolysis-GC and SEC Analysis. Because the $\beta$-O$4^{\prime}$ linkage is the most abundant lignin interunit connection and thioacidolysis is an analytical technique for a complete cleavage of all $\beta$-O- $4^{\prime}$ bonds into various lignin fragments, thioacidolysis was conducted followed by GC and SEC analysis of the fragments to further evaluate the LCC structures. ${ }^{40}$ The results of thioacidolysis-GC analysis showed that only the xylanlignin fraction contained detectable uncondensed monomeric lignin structures, while no uncondensed monomeric lignin structures could be detected in any of the glucan-lignin fractions that were analyzed (Table 2). This might imply that the lignin present in glucan-lignin fractions is more condensed than those in the xylan-lignin ones. As typically found in eucalyptus pulps, uncondensed $S$ units are more abundant than $\mathrm{G}$ units in the xylan-lignin fraction, the S:G ratio being 2.53.4. This ratio is lower than that found in wood lignin from eucalyptus $(4.1-4.9)^{37}$ but similar to that reported in ref 22 via Py-GC-MS of eucalyptus pulp, because of the pulping process during which $S$ units would be preferentially removed than $G$ units. In agreement with the results for the $\kappa$ number, the lignin modification effect of the MtL-MeS system was weaker than that of the PcL-HBT system. The uncondensed S and G unit contents of the xylan-lignin fraction of treated pulps compared to those from control pulp ( $\mathrm{pH} \mathrm{6)}$ decreased from 18 to 15 $\mu \mathrm{mol} / \mathrm{g}$ and from 7 to $5 \mu \mathrm{mol} / \mathrm{g}$, respectively. On the other hand, in xylan-lignin fractions from pulps treated with the PcL-HBT system, a stronger delignification effect was observed, and uncondensed $\mathrm{S}$ and $\mathrm{G}$ units were sharply reduced from 17 to $5 \mu \mathrm{mol} / \mathrm{g}$ and from 5 to $2 \mu \mathrm{mol} / \mathrm{g}$, respectively.

From the thioacidolysis-SEC analysis, the molecular mass distribution of all lignin fragments (as detected by UV detection at $280 \mathrm{~nm}$ ) was studied. Figure 2 shows that a buffer $\mathrm{pH} 4$ treatment (control $\mathrm{pH} 4$ ) could remove the fraction of 


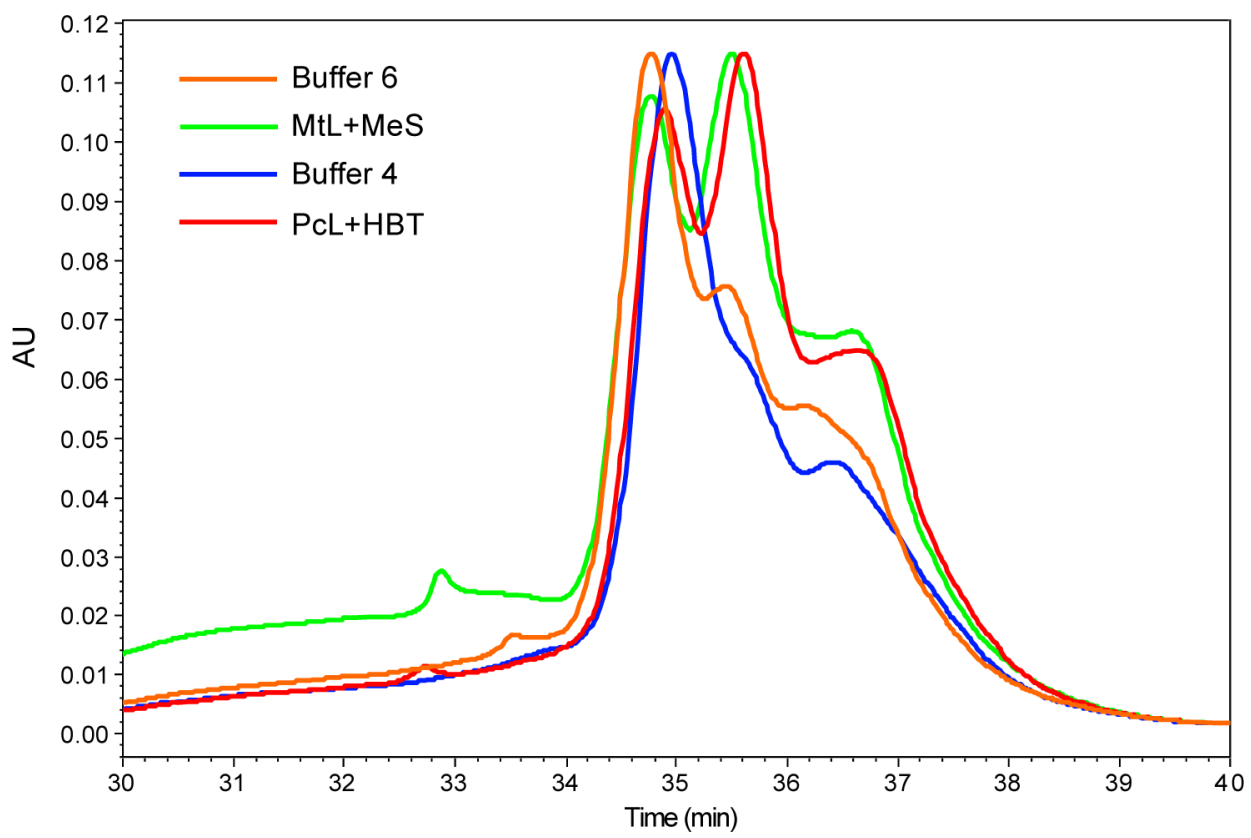

Figure 2. Thioacidolysis-SEC chromatograms of xylan-lignin fractions from blank experiments (buffer pH 6 and pH 4) and LMS treatments.

condensed lignin structure eluted at $33.6 \mathrm{~min}$ (present in control $\mathrm{pH} 6$ ), which would be responsible for the observation of a slight reduction ( 0.5 unit) in the $\kappa$ number mentioned above. This SEC analysis shows that both laccase-mediator treatments depolymerized the lignin, resulting in more fragments that eluted $>35.2 \mathrm{~min}$ after the thioacidolysis. They also polymerized the lignin by forming more fragments that eluted at $<34 \mathrm{~min}$, showing especially a large polymer fraction around 32.7-33 min in xylan-lignin fractions treated with both $\mathrm{MtL}-\mathrm{MeS}$ and $\mathrm{PcL}-\mathrm{HBT}$ systems. Interestingly, more polymeric fragments were found with the $\mathrm{MtL}-\mathrm{MeS}$ treatment by a larger peak area shown in the thioacidolysis-SEC chromatogram $<34$ min after peak normalization to make the comparison viable.

Py-GC-MS Analysis of LCC. Py-GC-MS is another sensitive technique that was used for a more detailed investigation of the changes in the lignin structures. The identities and relative abundances of all pyrolysis products, after performing single-ion integration because of the low intensity of their original total ion current (TIC) signals (cf. ref 21), are listed in Table 3. In sharp contrast to the thioacidolysis-GC analysis mentioned above, even the lignin structure in glucanlignin fractions could now be characterized because various $S$ and $\mathrm{G}$ unit fragments were detected from both LCCs. Upon comparison of the fragmentation patterns between pulp treated with the $\mathrm{MtL}-\mathrm{MeS}$ system and its control ( $\mathrm{pH} \mathrm{6}$ ), large increases of the amounts of syringol in both LCCs could be noticed, 17.4 and $12.4 \%$ in glucan-lignin fractions and $30.7 \%$ and $14.4 \%$ in xylan-lignin fractions, respectively. An increase in the $S: G$ ratio was previously reported as the result of PcLHBT treatment. ${ }^{21}$ However, if we include all the lignin fragments in the calculation of the $S: G$ ratio, we can conclude that there is actually no noticeable change in the $S: G$ ratio, except for that of the glucan-lignin fraction in the case of the $\mathrm{MtL}-\mathrm{MeS}$ system. For the PcL-HBT system, the ratio is always around 2.1-2.5 for all LCCs.

From the lignin fragments, obvious lignin oxidation by LMS could directly be noticed. In the case of the PcL-HBT system, $\mathrm{C} \alpha$ oxidation was observed in the xylan-lignin fraction because the amounts of all $\mathrm{C} \alpha$ carbonyl structures increased, reaching $23.9 \%$ compared with $13.3 \%$ in the control (Table 3 ). Such an evaluation method was reported in the literature. ${ }^{45}$ Here these carbonyl groups could be attributable solely to the oxidations during the laccase-mediator treatment because the pyrolysis process itself was performed under an inert gas atmosphere. Interestingly, this $\mathrm{C} \alpha$ oxidation could not be noticed in the glucan-lignin fraction or in the case of the MtL-MeS system. In the case of the MtL-MeS system, $\mathrm{C} \alpha-\mathrm{C} \beta$ bonding cleavage reactions could be noticed from both LCCs. Because of the cleavage that reduced the amounts of longer side chain structures than one carbon after the LMS treatment, there were obvious decreases in the levels of both $\mathrm{Ph}-\mathrm{C} 2$ and $\mathrm{Ph}-$ $\mathrm{C} 3$ fragments after pyrolysis. The amounts of $\mathrm{Ph}-\mathrm{C} 2$ and $\mathrm{Ph}-$ C3 fragments decreased from 27.5 to $21.9 \%$ and from 31.0 to $22.0 \%$ in the glucan-lignin fraction, respectively, and from 25.5 to $20 \%$ and from 30.6 to $24.3 \%$ in the xylan-lignin fraction, respectively. Interestingly, this $\mathrm{C} \alpha-\mathrm{C} \beta$ bonding cleavage could not be noticed for the case of the PcL-HBT system. Indeed, the two LMSs worked obviously differently from each other.

On the basis of the observations from this study and the knowledge reported in the literature, we could conclude that the lignin biodegradation mechanism with the LMS is as follows. For phenolic lignin structures, the initial enzymatic reaction would be the oxidation by laccase with $\mathrm{O}_{2}$ with or without a mediator leading to the formation of phenoxy radicals. ${ }^{9}$ Because nonphenolic units are as expected dominant in the residual lignin structures of chemical pulps, depending on the mediator application and the mediator structure applied, two possible routes are important to initiate radical structures in the nonphenolic units, the electron transfer (ET) route and hydrogen atom transfer (HAT) route. ${ }^{46}$ Both reactions lead to the formation of benzyl carbon-centered radicals of nonphenolic units.

With regard to the treatment with the PcL-HBT system, it is worth mentioning that the HBT used is among the most successful mediators found so far, and there is actually a radical HAT pathway as revealed by model experiments. ${ }^{46}$ The formation of the carbon-centered radicals of nonphenolic 
Table 3. Different Pyrolyzed Lignin Fragments and Their Relative Intensities (percent) from Blank Experiments (buffer pH 6 and $\mathrm{pH}$ 4) and LMS Treatments

\begin{tabular}{|c|c|c|c|c|c|c|c|c|c|c|c|}
\hline & \multirow[b]{2}{*}{ name } & \multirow[b]{2}{*}{ abbreviation } & \multirow[b]{2}{*}{$\begin{array}{l}\text { ion for } \\
\text { integration }\end{array}$} & \multicolumn{2}{|c|}{ buffer 6} & \multicolumn{2}{|c|}{$\mathrm{MtL}-\mathrm{MeS}$} & \multicolumn{2}{|c|}{ buffer 4} & \multicolumn{2}{|c|}{ PcL-HBT } \\
\hline & & & & $\begin{array}{c}\text { glucan- } \\
\text { lignin }\end{array}$ & $\begin{array}{c}\text { xylan- } \\
\text { lignin }\end{array}$ & $\begin{array}{c}\text { glucan- } \\
\text { lignin }\end{array}$ & $\begin{array}{c}\text { xylan- } \\
\text { lignin }\end{array}$ & $\begin{array}{c}\text { glucan- } \\
\text { lignin }\end{array}$ & $\begin{array}{c}\text { xylan- } \\
\text { lignin }\end{array}$ & $\begin{array}{c}\text { glucan- } \\
\text { lignin }\end{array}$ & $\begin{array}{c}\text { xylan- } \\
\text { lignin }\end{array}$ \\
\hline 1 & guaiacol & G & 124 & 3.4 & 5.0 & 11.7 & 4.8 & 3.5 & 5.4 & 3.6 & 5.2 \\
\hline 2 & 4-methylguaiacol & G-Me & 138 & 5.1 & 4.4 & 8.6 & 3.3 & 4.7 & 4.5 & 4.8 & 3.1 \\
\hline 3 & 4-ethylguaiacol & G-Et & 152 & 1.1 & 0.8 & 0.8 & 0.7 & 0.9 & 0.9 & 0.8 & 0.6 \\
\hline 4 & 4-vinylguaiacol & G-vinyl & 150 & 5.3 & 5.3 & 11.6 & 3.2 & 3.6 & 4.7 & 4.1 & 3.9 \\
\hline 5 & eugenol & $\mathrm{G}-\mathrm{C}-\mathrm{C}=\mathrm{C}$ & 164 & 1.3 & 1.3 & 0.5 & 0.7 & 1.1 & 1.2 & 1.2 & 1.0 \\
\hline 6 & 4-propylguaiacol & G-C-C-C & 166 & 0.3 & 0.2 & 1.0 & 0.2 & 0.4 & 0.1 & 0.0 & 0.1 \\
\hline 7 & isoeugenol (cis) & $\mathrm{G}-\mathrm{C}=\mathrm{C}-\mathrm{C}(\mathrm{cis})$ & 164 & 0.7 & 0.8 & 0.8 & 0.6 & 0.6 & 0.8 & 0.7 & 0.7 \\
\hline 8 & isoeugenol (trans) & $\mathrm{G}-\mathrm{C}=\mathrm{C}-\mathrm{C}($ trans $)$ & 164 & 4.4 & 5.4 & 6.6 & 3.0 & 3.8 & 4.6 & 4.3 & 3.8 \\
\hline 9 & vanillin & $\mathrm{G}-\mathrm{CHO}$ & 152 & 5.8 & 4.3 & 12.6 & 3.6 & 8.1 & 2.8 & 3.7 & 7.3 \\
\hline 10 & homovanillin & $\mathrm{G}-\mathrm{C}-\mathrm{CHO}$ & 162 & 2.7 & 0.8 & 0.0 & 0.5 & 2.5 & 1.0 & 1.7 & 0.4 \\
\hline 11 & acetoguaiacone & G-CO-C & 162 & 1.7 & 1.2 & 0.0 & 1.2 & 1.9 & 1.4 & 1.9 & 3.1 \\
\hline 12 & guaiacyl acetone & G-C-CO-C & 166 & 0.8 & 1.0 & 0.0 & 1.3 & 0.9 & 1.1 & 1.5 & 2.1 \\
\hline 13 & propioguaiacone & G-CO-C-C & 166 & 0.0 & 0.1 & 0.0 & 0.0 & 0.0 & 0.1 & 0.2 & 0.1 \\
\hline 14 & $\begin{array}{l}\text { 1-(4-hydroxy-3- } \\
\text { methoxyphenyl)prop-2-en-1- } \\
\text { one }\end{array}$ & $\mathrm{G}-\mathrm{CO}-\mathrm{C}=\mathrm{C}$ & 180 & 0.1 & 0.0 & 0.0 & 0.0 & 0.0 & 0.0 & 0.0 & 0.0 \\
\hline 15 & dihydroconiferyl alcohol & $\mathrm{G}-\mathrm{C}-\mathrm{C}-\mathrm{C}-\mathrm{OH}$ & 180 & 0.0 & 0.1 & 0.0 & 0.0 & 0.0 & 0.0 & 0.0 & 0.0 \\
\hline 18 & coniferaldehyde & $\mathrm{G}-\mathrm{C}=\mathrm{C}-\mathrm{CHO}$ & 180 & 0.0 & 0.2 & 0.0 & 0.0 & 0.5 & 0.0 & 0.0 & 0.0 \\
\hline 19 & syringol & $S$ & 154 & 12.4 & 14.4 & 17.4 & 30.7 & 12.7 & 16.8 & 14.4 & 14.5 \\
\hline 20 & 4-methylsyringol & $\mathrm{S}-\mathrm{Me}$ & 168 & 10.5 & 8.4 & 6.0 & 7.0 & 12.0 & 8.9 & 10.2 & 6.9 \\
\hline 21 & 4-ethylsyringol & S-Et & 182 & 2.0 & 1.2 & 0.0 & 1.2 & 2.7 & 1.8 & 2.2 & 1.3 \\
\hline 22 & 4-vinylsyringol & S-vinyl & 180 & 10.5 & 12.6 & 9.5 & 9.8 & 10.3 & 12.4 & 9.1 & 10.9 \\
\hline 23 & 4-allylsyringol & $\mathrm{S}-\mathrm{C}-\mathrm{C}=\mathrm{C}$ & 194 & 3.7 & 3.4 & 0.0 & 2.4 & 4.1 & 3.4 & 4.4 & 2.6 \\
\hline 24 & 4-propylsyringol & S-C-C-C & 196 & 0.7 & 0.4 & 0.0 & 0.4 & 0.8 & 0.5 & 0.8 & 0.4 \\
\hline 25 & 4-propenylsyringol (cis) & $\mathrm{S}-\mathrm{C}=\mathrm{C}-\mathrm{C}$ (cis) & 194 & 2.5 & 1.8 & 0.0 & 1.5 & 2.5 & 1.9 & 2.1 & 1.5 \\
\hline 26 & 4-propenylsyringol (trans) & $\mathrm{S}-\mathrm{C}=\mathrm{C}-\mathrm{C}($ trans $)$ & 194 & 13.5 & 12.9 & 9.7 & 8.8 & 14.5 & 13.0 & 13.2 & 10.0 \\
\hline 27 & syringaldehyde & $\mathrm{S}-\mathrm{CHO}$ & 182 & 4.3 & 7.5 & 0.0 & 6.3 & 2.0 & 6.3 & 5.0 & 9.3 \\
\hline 28 & homosyringaldehyde & $\mathrm{S}-\mathrm{C}-\mathrm{CHO}$ & 196 & 1.9 & 1.1 & 0.0 & 0.6 & 1.2 & 1.4 & 1.4 & 1.2 \\
\hline 29 & acetosyringone & $\mathrm{S}-\mathrm{CO}-\mathrm{C}$ & 196 & 2.3 & 2.5 & 0.0 & 2.8 & 2.2 & 2.2 & 3.2 & 3.5 \\
\hline 30 & syringyl acetone & $\mathrm{S}-\mathrm{C}-\mathrm{CO}-\mathrm{C}$ & 210 & 2.6 & 2.5 & 3.4 & 4.7 & 2.2 & 2.3 & 4.7 & 6.0 \\
\hline 31 & propiosyringone & S-CO-C-C & 210 & 0.4 & 0.5 & 0.0 & 0.7 & 0.6 & 0.5 & 0.8 & 0.6 \\
\hline & $\mathrm{S}: \mathrm{G}$ ratio & & & 2.1 & 2.2 & 0.8 & 3.3 & 2.1 & 2.5 & 2.5 & 2.2 \\
\hline & $\begin{array}{l}\text { total amount of } \mathrm{C} \alpha \text { carbonyl } \\
\text { structures }\end{array}$ & & & 14.6 & 16.1 & 12.6 & 14.6 & 14.8 & 13.3 & 14.8 & 23.9 \\
\hline & $\mathrm{Ph}-\mathrm{C} 2$ & & & 27.5 & 25.5 & 21.9 & 20.0 & 25.3 & 25.8 & 24.4 & 24.9 \\
\hline & $\mathrm{Ph}-\mathrm{C} 3$ & & & 31.0 & 30.6 & 22.0 & 24.3 & 32.0 & 29.5 & 33.9 & 28.9 \\
\hline
\end{tabular}

lignin units of both $S$ and $G$ units could be drawn as structures I as depicted in Figure 3. Subsequently, there is a nonenzymatic reaction of $\mathrm{O}_{2}$ attacking the carbon-centered radical intermediates, forming structures II $\alpha$ which are not stable and will give rise to a variety of reactions, such as $\mathrm{C} \alpha$ oxidation, $\mathrm{C} \alpha-\mathrm{C} \beta$ cleavage, and aromatic ring cleavage. ${ }^{47} \mathrm{C} \alpha$ oxidation leads to structures III, ${ }^{48}$ which explains the observations of more $\mathrm{C} \alpha$ carbonyl fragments obtained after pyrolysis of the LCCs obtained from the pulps treated with the PcL-HBT system. Because of the change at the $\mathrm{C} \alpha$ positions, the thioacidolysis will no longer lead to formation of "ordinary" G and $S$ uncondensed units that could be detected by thioacidolysisGC analysis. ${ }^{40}$ That is why smaller amounts of uncondensed G and $S$ units were observed in the analysis after the PcL-HBT treatment. Alternatively, the radical structures II $\boldsymbol{\alpha}$ abstract $\mathrm{H}$ atoms from a substrate, forming nonradical structures $\mathbf{I I} \boldsymbol{\beta}$. From $\mathrm{II} \boldsymbol{\beta}$, the cleavage between $\mathrm{C} \alpha$ and $\mathrm{C} \beta$ via Baeyer-Villiger reaction takes place, which reduces the molecular sizes of the lignin and generates structures $\mathbf{I V}$ and $\mathbf{V}$ with methoxybenzoic acid groups, as reported for the LMS treatment of the model dimer ${ }^{48}$ and the lignocellulose fungal treatment. ${ }^{49}$ This explains the observation of reduced amounts of $\mathrm{Ph}-\mathrm{C} 2$ and $\mathrm{Ph}-\mathrm{C} 3$ fragments after the Py-GC-MS analysis of the LMS-treated LCCs with the MtL-MeS system. Interestingly, a significant increase in the amount of syringic acid (identified as a methylated derivative by $\mathrm{Py}-\mathrm{GC}-\mathrm{MS}$ after using tetramethylammonium hydroxide as the derivatization reagent) was observed after both $\mathrm{MtL}-\mathrm{MeS}$ and $\mathrm{PcL}-\mathrm{HBT}$ treatments (not shown in Table 3 ). In the former case, this compound could be mainly derived from $\mathrm{MeS}$, but its significant increases in the treatment with PcL-HBT, from 1.0 to $2.4 \%$ (glucanlignin fraction) and from 2.4 to $6.2 \%$ (xylan-lignin fraction), support the formation from $S$ units during the LMS treatment. Chemically, the actual route of the LMS oxidation depends on the efficiency of the conversion of II $\boldsymbol{\alpha}$ to II $\boldsymbol{\beta}$, which needs a substrate to supply the $\mathrm{H}$ atom. Because $\mathrm{MeS}$ has a phenolic structure and may be a better $\mathrm{H}$ atom supplier than the HBT and a larger amount of $\mathrm{MeS}(6.75 \mathrm{mM})$ than HBT was applied ( $3 \mathrm{mM}$, see the Experimental Section), more $\mathrm{C} \alpha$ oxidation was noticed in the case of the PcL-HBT system and more $\mathrm{C} \alpha-\mathrm{C} \beta$ 


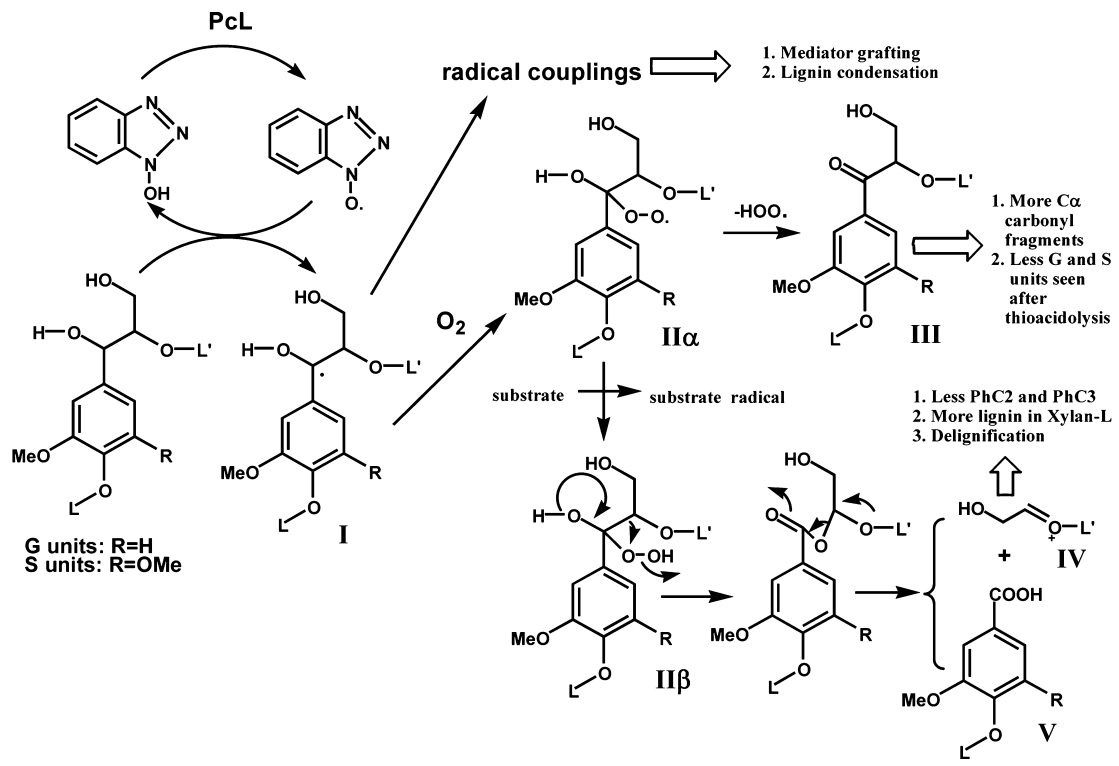

Figure 3. Biodegradation mechanism of the nonphenolic lignin structure by LMS treatment (e.g., PcL-HBT).

cleavage was noticed for the MtL-MeS system (by Py-GCMS). In addition, there are also subsequent or separate reactions to the $\mathrm{C} \alpha$ oxidation or $\mathrm{C} \alpha-\mathrm{C} \beta$ cleavage, leading to aromatic ring cleavage ${ }^{48}$ (not shown in Figure 3 ). From the radical structure $\mathbf{I}$, two other nonenzymatic reactions will take place: (1) eventual radical coupling with a mediator, which would result in $\mathrm{MeS}$ grafting, and (2) radical coupling among lignin radicals resulting in lignin condensation, one explanation of the more condensed structures seen by the thioacidolysisSEC analysis. Moreover, when the entire LCC structure becomes smaller, it will have a higher solubility in the DMSO-containing solution and be found in the xylan-lignin fractions. That is why the Klason lignin contents of the xylanlignin fractions increased after LMS treatments. If the lignin structure is degraded to such an extent that it becomes soluble in the LMS process solution, the pulp is delignified. This will result in a reduced pulp corrected $\kappa$ number, especially in the case of the PcL-HBT treatment where the lowest value of 6.3 was observed. With regard to the $\mathrm{MtL}-\mathrm{MeS}$ system, previous studies had shown that a sequence including alkaline extraction after LMS is required to obtain significant pulp delignification with this commercial laccase and natural mediator system. ${ }^{14}$

\section{CONCLUSION}

In light of the results obtained in this study, the lignin biodegradation reactions of the LMS include $\mathrm{C} \alpha$ oxidation into a keto structure, cleavage of $\mathrm{C} \alpha$ and $\mathrm{C} \beta$ carbon-carbon bonds, and aromatic ring cleavage. All reactions will eventually lead to lignin degradation and finally delignification of the chemical pulp. Different combinations of laccases and mediators will lead to differences in the actual oxidation routes and eventually differences in the total delignification effects. The characterization of trace and tracer amounts of lignin before and after LMS treatments, respectively, could be greatly improved by fractionation of lignin-carbohydrate complexes followed by applications of highly sensitive analytical techniques such as thioacidolysis-GC and -SEC and Py-GC-MS analyses so that more comprehensive lignin structural information could be obtained.

\section{AUTHOR INFORMATION}

\section{Corresponding Author}

*E-mail: jbing@kth.se.

\section{Notes}

The authors declare no competing financial interest.

\section{ACKNOWLEDGMENTS}

This study was financially supported by the EU BIORENEW Project (NMP2-CT-2006-026456). Novozymes (Bagsvaerd, Denmark) and Beldem (Andenne, Belgium) are acknowledged for the M. thermophila and P. cinnabarinus laccases, respectively. J. Romero (ENCE) is acknowledged for providing the eucalyptus pulp samples and E. D. Babot for performing the enzymatic treatments. J.R. acknowledges the CSIC JAE-Doc contract of the program "Junta para la Ampliación de Estudios" cofinanced by the European Social Fund (ESF).

\section{REFERENCES}

(1) Tien, M.; Kirk, T. K. Science 1983, 221, 661-662.

(2) Kuwahara, M.; Glenn, J. K.; Morgan, M. A.; Gold, M. H. FEBS Lett. 1984, 169, 247-250.

(3) Camarero, S.; Sarkar, S.; Ruiz-Duenas, F. J.; Martinez, M. J.; Martinez, A. T. J. Biol. Chem. 1999, 274, 10324-10330.

(4) Ruiz-Duenas, F. J.; Martinez, A. T. Microb. Biotechnol. 2009, 2, 164-177.

(5) Yaropolov, A. I.; Skorobogatko, O. V.; Vartanov, S. S.; Varfolomeyev, S. D. Appl. Biochem. Biotechnol. 1994, 49, 257-280.

(6) Solomon, E. I.; Sundaram, U. M.; Machonkin, T. E. Chem. Rev. 1996, 96, 2563-2605.

(7) Giardina, P.; Faraco, V.; Pezzella, C.; Piscitelli, A.; Vanhulle, S.; Sannia, G. Cell. Mol. Life Sci. 2010, 67, 369-385.

(8) Canas, A. I.; Camarero, S. Biotechnol. Adv. 2010, 28, 694-705.

(9) Higuchi, T. Proc. Jpn. Acad., Ser. B 2004, 80, 204-214.

(10) Kirk, T.; Cullen, D. Enzymology and molecular genetics of wood degradation by white-rot fungi. In Environmentally friendly technologies for the pulp and paper industry; Young, R., Akhtar, M., Eds.; TAPPI: Atlanta, 1998; pp 273-308.

(11) Bourbonnais, R.; Paice, M. G. FEBS Lett. 1990, 267, 99-102.

(12) Nousiainen, P.; Maijala, P.; Hatakka, A.; Martinez, A. T.; Sipila, J. Holzforschung 2009, 63, 699-704.

(13) Fillat, A.; Roncero, M. B.; Vidal, T. J. Chem. Technol. Biotechnol. 2011, 86, 1501-1507. 
(14) Babot, E. D.; Rico, A.; Rencoret, J.; Kalum, L.; Lund, H.; Romero, J.; del Rio, J. C.; Martinez, A. T.; Gutierrez, A. Bioresour. Technol. 2011, 102, 6717-6722.

(15) Valls, C.; Cadena, E. M.; Roncero, M. B. Carbohydr. Polym. 2013, 92, 276-282.

(16) Fillat, U.; Prieto, A.; Camarero, S.; Martinez, A. T.; Martinez, M. J. Biochem. Eng. J. 2012, 67, 97-103.

(17) Xu, F.; Kulys, J. J.; Duke, K.; Li, K. C.; Krikstopaitis, K.; Deussen, H. J. W.; Abbate, E.; Galinyte, V.; Schneider, P. Appl. Environ. Microb. 2000, 66, 2052-2056.

(18) Li, K. C.; Xu, F.; Eriksson, K. E. L. Appl. Environ. Microb. 1999, 65, 2654-2660.

(19) Camarero, S.; Garcia, O.; Vidal, T.; Colom, J.; del Rio, J. C.; Gutierrez, A.; Gras, J. M.; Monje, R.; Martinez, M. J.; Martinez, A. T. Enzyme Microb. Technol. 2004, 35, 113-120.

(20) Fillat, A.; Colom, J. F.; Vidal, T. Bioresour. Technol. 2010, 101, 4104-4110.

(21) Camarero, S.; Ibarra, D.; Martinez, A. T.; Romero, J.; Gutierrez, A.; del, R. J. C. Enzyme Microb. Technol. 2007, 40, 1264-1271.

(22) Ibarra, D.; Romero, J.; Martinez, M. J.; Martinez, A. T.; Camarero, S. Enzyme Microb. Technol. 2006, 39, 1319-1327.

(23) Gutierrez, A.; del Rio, J. C.; Ibarra, D.; Rencoret, J.; Romero, J.; Speranza, M.; Camarero, S.; Martinez, M. J.; Martinez, A. T. Environ. Sci. Technol. 2006, 40, 3416-3422.

(24) Gutierrez, A.; del Rio, J. C.; Rencoret, J.; Ibarra, D.; Martinez, A. T. Appl. Microbiol. Biot. 2006, 72, 845-851.

(25) Valls, C.; Molina, S.; Vidal, T.; del Rio, J. C.; Colom, J. F.; Martinez, A. T.; Gutierrez, A.; Roncero, M. B. Process Biochem. 2009, 44, 1032-1038.

(26) Gutierrez, A.; Rencoret, J.; Cadena, E. M.; Rico, A.; Barth, D.; del Rio, J. C.; Martinez, A. T. Bioresour. Technol. 2012, 119, 114-122.

(27) Areskogh, D.; Li, J.; Gellerstedt, G.; Henriksson, G. Biomacromolecules 2010, 11, 904-910.

(28) Barneto, A. G.; Valls, C.; Ariza, J.; Roncero, M. B. Bioresour. Technol. 2011, 102, 9033-9039.

(29) Speranza, M.; Ibarra, D.; Romero, J.; Martinez, A. T.; Martinez,

M. J.; Camarero, S. Biocatal. Biotransform. 2007, 25, 251-259.

(30) Sealey, J.; Ragauskas, A. J. Enzyme Microb. Technol. 1998, 23, $422-426$.

(31) Ibarra, D.; Chavez, M. I.; Rencoret, J.; del Rio, J. C.; Gutierrez, A.; Romero, J.; Camarero, S.; Martinez, M. J.; Jimenez-Barbero, J.; Martinez, A. T. Holzforschung 2007, 61, 634-646.

(32) Liu, N.; Shi, S. L.; Gao, Y.; Qin, M. H. Enzyme Microb. Technol.

2009, 44, 89-95.

(33) del Rio, J. C.; Gutierrez, A.; Romero, J.; Martinez, M. J.; Martinez, A. T. J. Anal. Appl. Pyrolysis 2001, 58, 425-439.

(34) Du, X.; Gellerstedt, G.; Li, J. Plant J. 2013, 74, 328-338.

(35) Lawoko, M.; Henriksson, G.; Gellerstedt, G. Biomacromolecules 2005, 6, 3467-3473.

(36) Du, X.; Eugenio Martin, M. E.; Li, J. Holzforschung 2013, DOI: $10.1515 / \mathrm{hf}-2012-0140$.

(37) Li, J. B.; Martin-Sampedro, R.; Pedrazzi, C.; Gellerstedt, G. Holzforschung 2011, 65, 43-50.

(38) Gellerstedt, G.; Li, J. B. Carbohydr. Res. 1996, 294, 41-51.

(39) Gellerstedt, G. Gel Permeation Chromatography. In Methods in lignin chemistry; Lin, S., Dence, C., Eds.; Springer-Verlag: Heidelberg, Germany, 1992; pp 487-497.

(40) Rolando, C.; Monties, B.; Lapierre, C. Thioacidolysis. In Methods in lignin chemistry; Lin, S. Y., Dence, C. W., Eds.; SpringerVerlag: Heidelberg, Germany, 1992; pp 334-349.

(41) Berka, R. M.; Schneider, P.; Golightly, E. J.; Brown, S. H.; Madden, M.; Brown, K. M.; Halkier, T.; Mondorf, K.; Xu, F. Appl. Environ. Microb. 1997, 63, 3151-3157.

(42) Li, J.; Gellerstedt, G. Nord. Pulp Pap. Res. J. 1998, 13, 153-158.

(43) Li, J.; Gellerstedt, G. Carbohydr. Res. 1997, 302, 213-218.

(44) Cadena, E. M.; Du, X.; Gellerstedt, G.; Li, J.; Fillat, A.; GarciaUbasart, J.; Vidal, T.; Colom, J. F. Bioresour. Technol. 2011, 102, 39113917.
(45) Ohra-aho, T.; Tenkanen, M.; Tamminen, T. J. Anal. Appl. Pyrolysis 2005, 74, 123-128.

(46) Fabbrini, M.; Galli, C.; Gentili, P. J. Mol. Catal. B: Enzym. 2002, $16,231-240$.

(47) Kawai, S.; Umezawa, T.; Higuchi, T. Arch. Biochem. Biophys. 1988, 262, 99-110.

(48) Kawai, S.; Nakagawa, M.; Ohashi, H. Enzyme Microb. Technol. 2002, 30, 482-489.

(49) Camarero, S.; Galletti, G. C.; Martinez, A. T. Rapid Commun. Mass Spectrom. 1997, 11, 331-334. 